\title{
Flexible borders-Co-creation in an interprofessional team: Caring for patients with ALS in a palliative context
}

\author{
Berit Kilde ${ }^{1}$, Bjørg Th. Landmark ${ }^{2,3}$, Ellen Karine Grov ${ }^{* 4}$ \\ ${ }^{1}$ Department of Nursing and Health Care, Ål municipality, Ål, Norway \\ ${ }^{2}$ Institute of Research and Development for Nursing and Care Services, Drammen municipality, Drammen, Norway \\ ${ }^{3}$ Institute of Nursing Science, Faculty of Health Sciences, University College South-East, Drammen, Norway \\ ${ }^{4}$ Department of Nursing and Health Promotion, Faculty of Health Sciences, Oslo and Akershus University College of Applied \\ Sciences, Oslo, Norway
}

Received: August 10, 2016

DOI: $10.5430 /$ jnep.v7n2p126
Accepted: September 21, $2016 \quad$ Online Published: October 20, 2016

URL: http://dx.doi.org/10.5430/jnep.v7n2p126

\begin{abstract}
Introduction: The municipal health services have been given greater responsibility for an increasing number of younger patients with neurological diseases. This has created new challenges regarding the use of resources and skills, in addition to co-ordination and organization of health services. Amyotrophic Lateral Sclerosis (ALS) leads to considerable loss of function. These patients are in need of care from interprofessional health teams; from municipal health services and specialists in hospital service.
\end{abstract}

Aim: To investigate how health professionals from municipal and specialist health services experience interprofessional cooperation when caring for home-dwelling patients with ALS in the palliative phase.

Methods: Design: An exploratory design with a qualitative approach, theoretically inspired by perspectives on interprofessional cooperation and person-centered care, was used. Material and methods: Data collection was carried out during four focus group interviews, consisting of twenty-three participants. Analyses were performed using Malterud's and Kvale and Brinkmann's approaches.

Results: Team building and cooperative fellowship were important preconditions for the provision of interprofessional services to meet patients with ALS' individual needs and desires. Throughout the disease trajectory patients with ALS present a diversity of problems. In order to provide relevant services during the palliative phase, staff changes should be avoided, the coordinator role should be clarified, and palliative skills must be developed. Co-creation and flexibility are essential to provide unique, person-centered services for patients with ALS and their families.

Conclusions: Health personnel face challenges related to cooperating across health system borders. Addressing pit-falls of responsibility, the interprofessional team highlights co-creation and flexibility. Successful cooperation occurs when personcenteredness and flexibility are jointly used to co-create in clinical practice.

Key Words: Amyotrophic Lateral Sclerosis (ALS), Palliative care, Health personnel, Co-creation, Collaboration, Interprofessional teams

*Correspondence: Ellen Karine Grov; Email: Ellen-Karine.Grov@ @ioa.no; Address: Department of Nursing and Health Promotion, Faculty of Health Sciences, Oslo and Akershus University College of Applied Sciences, Oslo, Norway. 


\section{INTRODUCTION}

Due to better treatment strategies and follow-up, the number of patients with demanding needs and complex diseases, as Parkinson's disease and Multiple sclerosis, has increased threefold during the last 20 years. This implies that health personnel need to improve competence and skills in order to facilitate the provision of satisfactory services to these target groups. ${ }^{[1-3]}$ Specialized palliative home care has, so far, most often addressed patients with cancer and their caregivers. However, internationally there is a shift to encourage greater focus on treatment and care for patients with other serious, long-term conditions, such as Amyotrophic Lateral Sclerosis (ALS) ${ }^{[4]}$ Despite international consensus on the need to integrate palliative care into the patients with ALS disease trajectory, large variations exist from country to country. ${ }^{[5]}$

ALS is a progressive, incurable neurological disease, causing extensive loss of muscular function. ${ }^{[2,6,7]}$ Symptoms include muscle weakness, muscular atrophy, spasticity, weight loss, swallowing difficulties, nutritional problems, speech and communication difficulties and respiratory failure. The psychological burden can be heavy, and anxiety and unrest are natural forms of response for those afflicted with ALS. The complexity of symptoms demands interprofessional cooperation. ${ }^{[2,6,8]}$

The treatment of and care for patients with ALS require both a specialized and general approach. ${ }^{[2]}$ Specialist ALS-teams most often include a neurologist, a pulmonary physician, a clinical nurse specialist, an occupational therapist, a physiotherapist, a speech therapist, a psychologist and a palliative physician. ${ }^{[6]}$ The patients' general practitioner (GP), local municipal nursing services, occupational therapist and physiotherapist services care for patients living at home, and offer support to relatives. Challenges facing local health services are most often related to poor staff-continuity and a lack of competence, especially when patients have complex, extensive needs for treatment and care. ${ }^{[9]}$ Patients with ALS approaching the end-of-life need specialized symptom control and increased support related to activities of daily living (ADL). In order to provide adequate support, interprofessional cooperation between the specialist and primary health care services must be systematically organized. ${ }^{[5,6,8]} \mathrm{Ng}$ et al. ${ }^{[8]}$ developed a model where the neurologist and palliative team, based in specialist hospital services, cooperate with municipal health personnel during the diagnostic, rehabilitation and palliative phases. They also introduced a new concept neuropalliative rehabilitation. This concept includes central components, such as understanding the development of the disease, symptom control, coping strategies, communication challenges, end-of-life challenges, equipment needs, advice

Published by Sciedu Press and support. ${ }^{[8]}$

In order to enhance the patients' quality of life, the interprofessional team needs to adopt an individual, unique, personcentered approach. A person-centered approach supports the patients' involvement in terms of an emancipatory practice development in action by providing family caregivers and the interprofessional team the opportunity to create a caring culture. According to McCormack \& McCance, ${ }^{[10]}$ person-centered care is an approach established through the formation and fostering of therapeutic relationships between all care providers, patients, and others significant to them. Person-centered care is supported by values such as respect for individuals' rights to self-determination, mutual respect and understanding. However, studies conclude that there is a need for further research on the meaning of interprofessional cooperation, the understanding of ALS and the development of neurological, rehabilitation and palliative services. ${ }^{[3,6,8,11]}$ The aim of this study is therefore, from the perspectives of health personnel working in specialist and local health care, to investigate experiences of interprofessional collaboration when providing services to patients with ALS living at home in the palliative phase.

\section{METHOD}

The study has an exploratory design with a qualitative approach. The aim was to gain a deeper understanding of interprofessional cooperation in a palliative context, where research aims to uncover nuances in participants' subjective perceptions, thoughts, motives and opinions. ${ }^{[12]}$ Focus groups were used as a method for data collection. Focus group interviews were chosen because this method is well suited for studies that aim to uncover experiences, attitudes or perspectives within an environment where many people cooperate. ${ }^{[13]}$

Focus groups are characterised by group interactions that are based on a topic chosen by the researcher as the main focus of dialogue ${ }^{[14]}$ Dynamics emerging from a dialogue between group participants and provide new and varied insight into the topic - insight gained from the group interviewed. ${ }^{[13]}$ In this study, the first author was the moderator, while an assistant moderator observed the group and ensured that all the points in the interview guide were covered in the dialogue.

Upon completion of each group session, the moderator and assistant moderator summarized the interactions between the group members. The impression of the group as a whole was taken note of, the content of the group interview was documented to see which themes had been addressed, and questions to be discussed during the following focus group meeting were identified. 
Topics noted for inclusion in the interview guide consisted of the following: participants' experience of interprofessional cooperation both within and between municipal and specialist levels, the structure of cooperation, coordination in practice, and the transfer of competency and skills. Focus group meetings lasted 70-90 minutes and the interviews were tape recorded.

Table 1. Sample background

\begin{tabular}{|c|c|c|}
\hline & Municipal Health Services & Specialist Health Services \\
\hline \multirow{2}{*}{ Participants } & 1 group of 6 participants & 1 group of 4 participants \\
\hline & 1 group of 7 participants & 1 group of 6 participants \\
\hline Mean age & 42 years & 39 years \\
\hline Profession & $\begin{array}{l}\text { Physiotherapist (3), GP (3), Registered nurse } \\
\text { (4), Pulmonary technician (1), Occupational } \\
\text { therapist (1), Palliative nurse (1) }\end{array}$ & $\begin{array}{l}\text { Physiotherapist (1), Specialist in occupational therapy (1), } \\
\text { Occupational therapist (1), Pulmonary nurse (1), Registered nurse } \\
\text { (2), Speech therapist (1), Social worker (1), Medical doctor (2) }\end{array}$ \\
\hline $\begin{array}{l}\text { Work } \\
\text { experience }\end{array}$ & $\begin{array}{l}3 \text { yrs*, } 9 \text { yrs, } 25 \text { yrs, } 26 \text { yrs, } 6 \text { yrs, } \\
33 \text { yrs, } 16 \text { yrs, } 26 \text { yrs, } 14 \text { yrs, } 3 \text { yrs, } \\
5 \text { yrs, } 12 \text { yrs, } 26 \text { yrs }\end{array}$ & $\begin{array}{l}17 \text { yrs, } 12 \text { yrs, } 14 \text { yrs, } 6 \text { yrs, } \\
14 \text { yrs, } 20 \text { yrs, } 8 \text { yrs, } 4 \text { yrs, } \\
25 \text { yrs, } 23 \text { yrs }\end{array}$ \\
\hline
\end{tabular}

\subsection{Analysis}

As the study has an explorative aim, the analysis is thematic, crosswise and computerized. To achieve trustworthiness, every interview was read and interpreted by each researcher, and afterwards by the researchers in collaboration. A hermeneutic perspective provided guidelines for interpretation. ${ }^{[15]}$ Each interview was read several times to obtain an immediate impression of patterns and themes. Thereafter, text was separated into meaning units, which were then condensed. The condensed, meaning units were coded and given short names in order to describe the units in a general manner.

\subsection{Sample}

Following a strategic selection, four focus group interviews were carried out with a total of 23 participants. An overview of the sample is given in Table 1. Three groups included both men and women, whilst one group included only women. The amount of the participants' work experience varied from just under three years to over thirty years.
The codes were then sorted to create a basis for categories describing the core content of each focus group interview. When the same procedure had been applied to all four focus group interviews, the categories were compared and analyzed. Categories were then sorted in order to describe what was experienced as common and basic to the participants' experiences. ${ }^{[15-17]}$

Table 2 provides examples from the focus group interviews that illustrate the two categories, joint cooperation and competency. This gives credibility to the process of analysis. ${ }^{[18]}$

Table 2. Examples of thematic coding and categorizing in focus group \#3

\begin{tabular}{|c|c|c|}
\hline \multicolumn{3}{|l|}{ Focus group \#3 Theme: Interdisciplinary cooperation } \\
\hline Quote & Coding & Categorizing \\
\hline $\begin{array}{l}\text { "What do I think about interprofessional cooperation? It's } \\
\text { when people within different professions come together to } \\
\text { cooperate to the benefit of the patient - when such people } \\
\text { exchange experiences and talk together. In contrast, in } \\
\text { multidisciplinary cooperation, one cooperates, but works more } \\
\text { by himself.” }\end{array}$ & $\begin{array}{l}\text { - Different professions } \\
\text { - Common aim } \\
\text { - Common tasks }\end{array}$ & $\begin{array}{l}\text { Joint cooperation with } \\
\text { goals focus. }\end{array}$ \\
\hline $\begin{array}{l}\text { “...having a team is beneficial as it gives strength. We don't } \\
\text { stand alone in this. If we didn't have the interprofessional } \\
\text { team, a team that we can lean on, things would be a lot } \\
\text { harder.” } \\
\text { “...the team gives us strength. We dare to talk about what can } \\
\text { be expected.” }\end{array}$ & $\begin{array}{l}\text { - Strength and support from the team } \\
\text { - Exchange of experience } \\
\text { - Empowered health professionals in } \\
\text { the team } \\
\text { - Clarity in communication }\end{array}$ & $\begin{array}{l}\text { Team spirit supports } \\
\text { professional ability and } \\
\text { competency through } \\
\text { communication. }\end{array}$ \\
\hline
\end{tabular}


Cooperation in each focus group was analyzed crosswise, as illustrated by the examples in Table 3 . The analysis questions are inspired by Wibeck, Dahlgren \& Öberg. ${ }^{[19]}$ In Table 3, we present how the categories are organized and interpreted in context of content analysis, illustrated using two questions. The analysis is presented in three levels: interpretation, coding and categorizing.

Table 3. Examples of crosswise analysis

\begin{tabular}{llll}
\hline Analysis questions & Interpretation & Coding & Categorizing \\
\hline $\begin{array}{l}\text { To which degree did } \\
\text { the group address the } \\
\text { subject/topic? }\end{array}$ & $\begin{array}{l}\text { High level of interest regarding the topics of } \\
\text { cooperation, patient-centered practice, } \\
\text { documentation and organization. } \\
\text { Silence and less discussion regarding topics } \\
\text { linked to palliative services. }\end{array}$ & $\begin{array}{l}\text { Interest in patient-centered practice } \\
\text { and good services. } \\
\text { Unclear understanding and } \\
\text { conception of palliative services. }\end{array}$ & $\begin{array}{l}\text { Joint } \\
\text { cooperation } \\
\text { solve disagreements? }\end{array}$ \\
& $\begin{array}{l}\text { Increased discussion and interest where other } \\
\text { group members voiced opinions. } \\
\text { Some persons dominated the discussion. }\end{array}$ & $\begin{array}{l}\text { Clear acceptance of disagreements. } \\
\text { Development of competency } \\
\text { through interprofessional team } \\
\text { communication. }\end{array}$ \\
\hline
\end{tabular}

\subsection{Ethical considerations}

Norwegian Social Science Data Services AS (NSD) assessed and gave permission for this study to be carried out (project number: 33923). The study was conducted in accordance with the Helsinki Declaration demands for ethical standards. ${ }^{[20]}$ Written informed consent was obtained from the participants prior to the focus group interviews.

\section{RESUlts}

As a result from the analysis, categories emerged and from the health personnel's perspective, their experiences were related to interprofessional teamwork. Health personnel's experience of interprofessional teamwork can be divided into the following four categories:

(1) Structural frames

(2) Joint cooperation

(3) Competence

(4) The right place, at the right time

The four categories, however, should be seen as an intertwined whole.

\subsection{Structural frames}

The informants highlight the importance of system and structure in order to ensure continuity in, and good quality of services. The patients' situations are unpredictable, and flexibility is necessary in order to maintain continuity. The participants' descriptions illustrate how structural frames and organization of services both can enhance and hinder flexibility in the provision of services for patients with ALS living at home. Staff work-routines with fixed hours of duty, and staff rotation, can cause obstacles in serving patients with ALS' needs. A GP said:

Published by Sciedu Press

\begin{abstract}
"The way we have organized ourselves workwise, is the enemy of continuity and good treatment of a dying patient. I think we could rather work overtime for certain periods, and have more time off afterwards. We must try to climb out of the work-routine pattern because we have far too much of it. I think we are much too focused on time: "It's now half-past three - time to change staff and for me to go home." The patient might be in need of something complicated that should be dealt with by staff that knows the patient and the situation. It's not the patients' needs that drive us - it's our own needs, or our employer's need to structure a seven-and-a-half hour working day."
\end{abstract}

Data from the interviews showed that patients with ALS' needs can inspire health providers to change their ideas about borders and frames. Structural frames may limit problem solving, and data showed that health personnel take action beyond rigid frames. A medical doctor summarized as follows:

“... when we see that there is a need, we create space. Other things are set aside."

Data revealed that organizations and documentation tend to contribute to structure. However, this is not enough in situations when new challenges regarding patients with ALS' conditions constantly arise. Some participants described how they at times made internal agreements, supported and helped one another by maintaining close dialogue during on-going teamwork. A GP explained that municipal health services are difficult to organize in a hectic end-of-life situation. 
"This is a situation that is difficult to organize as it requires solving new challenges as they arise on an hourly and daily basis. In a way, one is forced to withstand the fact that not all jointcooperation can be organized and structured the entire way through. In the last stage, one has to be able to cope with unexpected events and improvise..."

\subsection{Joint cooperation}

Results showed that health personnel build relationships with each other, to the patient, to the patient's next-of-kin and to the rest of the network over time.

"It's a process where you get acquainted more and more over time as the disease progresses, and the diagnosis becomes clearer." (A physiotherapist in municipal health service)

As members of an established team with a good understanding of each other's strengths, several participants described how team spirit gave them the courage to provide care. They managed to use their experiences in clear communication with patients.

"We dare because we are members of this team. We dare to talk to the patient about what may be waiting around the next corner." (A nurse in municipal health service)

The informants highlighted the significance of network, both the patients' next-of-kin and the network of colleagues in joint cooperation.

"What kinds of resources are available? The interprofessional team is responsible for the organization of treatment, but the family, neighbors and work colleagues are also important and can be of great support. Some of these resources are natural to include in the teamwork. The partner might be very close to the patient and involved in the treatment. However, other resources are also important to have 'on board' as part of the collective effort." (A GP in municipal health service)

\subsection{Competence}

A deeper understanding of the significance of interprofessional cooperation was gained upon reflection in the focus groups. Also, awareness of the importance of transference of competence and skills, both internally at a municipal level and externally between a specialist and municipal health professionals, increased. 130
"We start a dialogue with the patients' local communities earlier than before. We communicate as we go along: What can the local community provide, and what is important for the patient? It's obvious that we do not know about all the different options and services available in all the municipalities, but we have to identify the existing competence available in the respective municipality as needs arise. There's quite a variety in the services that are available in the different municipalities." (Nurse coordinator for specialist health services)

"When you face the diagnosis the first time, you have to search for sources of competence; the hospitals or palliative units having such particular experience." (A GP in municipal health service)

The informants highlighted the process of mutual interaction between health professionals as competency is transferred. The specialist health service, especially the nurse coordinator, needs to know about services for patients with ALS provided by the local community, and visa-versa.

Results illuminated that, within the same level of service, the development of competency and skills is about learning from one another in real-life situations and looking for solutions as a team.

"I like working together with other people. I enjoy that. It's wonderful to talk to a colleague, ask questions or tell what I know about what has happened or can happen." (A specialist in Occupational Therapy)

\subsection{The right place, at the right time}

Data showed that experience gained by the specialist health service has had an impact on the quality of communication with patients with ALS. To find the right time to talk about each topic is a valued palliative approach, and a factor that became clearer during the focus group interviews.

"When the patient for example experiences speech difficulties, I wait to talk about communication aids as this is a sore matter in such a situation. Perhaps I know more about the right timing to bring up such a matter, compared to those who don't have the same experience, and raise the subject either too early or too late." (Nurse in specialist health service)

ISSN 1925-4040 E-ISSN 1925-4059 
Presence and availability emerge as important attributes for health personnel providing security and reassurance for patients as death approaches.

"In such a situation, we do as we always do. We keep focus, notice the small nuances, observe the progression and are prepared for what's to come. The most important thing is to just be present, to stand by, and tolerate the sad days." (Nurse in municipal service)

According to the informants, the palliative team at the hospital is available if needed by the local interprofessional team or the specialist ALS-team. However, services rendered by the specialist health services are rarely used by the municipal health services. Some of the informants mentioned that, for patients with ALS, there is a limited need for the specialist palliative team. Others stated that palliative competence is available as part of the interprofessional team established at a municipal level.

Whether a patient dies in the hospital or at home is not crucial for palliative treatment and care. Participants from municipal and specialist health services stated that they, in most cases, could cope with palliative challenges at the end-of-life stage. The home care nurses are available day and night. As one medical specialist said:

"There is a lot of palliative competence in the department here. However, patients with ALS die at home. I think this is because they receive adequate follow-up at home. Staying at home is more harmonious for them, and perhaps in accordance with their own wishes."

\section{Discussion}

From the perspective of health personnel working in specialist and municipal health care services, the aim of this study was to explore staff experiences of interprofessional collaboration when caring for patients with ALS living at home in the palliative phase. Four categories emerged: structural frames, joint cooperation, competence and the right place, at the right time. On the basis of these four, intertwined categories, experiences of interprofessional cooperation between health personnel attending to patients with ALS in the palliative phase will be discussed. The discussion is a synthesis of the four categories, with an overarching perspective on the concept of co-creation.

\subsection{Co-creation}

Co-creation is an interactive process based on trust and the sharing of knowledge, skills and information in open systems that encourage health personnel to adapt services to meet the

Published by Sciedu Press patients' needs. Co-creation can also be seen as a method of cooperation based on common values and goals. Prahalad and Ramaswamy ${ }^{[21]}$ claim that co-creation is about establishment of new relationships between different players. In this study, co-creation emerges as a basic value across roles, activities and different levels of health service. These factors are also highlighted by Bergdahl et al. ${ }^{[22]}$ who claim that co-creation is an approach towards achievement of important goals for patients living at home in the palliative phase.

The results show that interprofessional cooperation with a holistic focus provides valuable experience for the team as a whole. As we interpret, the team creates something meaningful for the patients with ALS, for the patient's next-of-kin and for themselves. According to official documents, interprofessional cooperation is fundamental to palliation, where different professions share common values and work together to achieve common goals. ${ }^{[4]}$ Co-creation can be understood as an interprofessional approach that is emphasized in palliative care, with a holistic philosophy as the basic ideology and a precondition for person-centeredness. ${ }^{[10]}$

Bergdahl et al. ${ }^{[22]}$ point out that the ideal for palliative care corresponds to the person-centered approach. In light of the results from this study, we ought to figure out what concretizes these values, particularly regarding awareness in clinical practice. The palliative team is rarely involved with the interprofessional teams providing service to patients with ALS living at home in the palliative phase. This study shows that structural frames cannot govern patient needs, even though health personnel must relate to such structures. A person-centered approach demands flexibility. If the structural frames are too rigid to allow for flexibility, the opportunity for co-creation becomes limited. When inspired individuals co-create to meet patients' needs - despite structural frames - this ideological commitment between the staff is met. The results also demonstrated that the health personnel was flexible in relation to structural frames at a system level, exemplified by spontaneous changes to staff-routines and the crossing of organizational boundaries. As this study indicates, increased focus on the patient encourages innovation and facilitates the crossing of organizational borders. A flexible attitude held by individual health personnel, and by the team as a whole, secures high quality services to this group of patients. In their study, $\mathrm{Ng}$ et al ${ }^{[8]}$ point to interprofessional cooperation as a central value for provision of coordinated treatment and care in the interface between neurology, rehabilitation and palliation. From Canada, Bainbridge et al. ${ }^{[23]}$ refer to their study on formal and informal palliative care networks and highlight the high value they place on working collaboratively. 
Close relationships improve creative interprofessional cooperation and support development of competency. We therefore consider fellowship as a basis for developing and strengthening competence and skills and for the provision of quality in services rendered to patients with ALS living at home. Results from this study reveal that specialist and municipal health services need to learn from each other and focus on the dissemination of knowledge between different levels of service. Competence is developed both in and between teams as an innovative process of co-creation. These findings are supported by previous studies and are dependent on trust between team members and interprofessional cooperation, both internally and across organizational levels of service provision. ${ }^{[5,6,21]}$

Being part of a team caring for home-dwelling patients with ALS can be a dynamic process. Changes to the team cause new challenges in the building of relationships, the definition of roles and the development of expertise. ${ }^{[1]}$ The importance of building relations to promote cooperation and team development is confirmed in other studies. Another study showed that, through mutual trust, teamwork and coordination, the members experienced effective teamwork. ${ }^{[2]}$ The opposite occurred when goals were non-existent, the definition of roles and delegation of tasks were unclear, and when team commitment was low. Further, Klarare et al. ${ }^{[25]}$ and Bainbridge et al. ${ }^{[23]}$ state that communication is the key to the successful resolution of a conflict and the implementation of tasks.

The results from this study show that there are high demands for advanced expertise in order to address patients with ALS' needs for holistic symptom relief. Health professionals' involvement in decision-making and challenges related to a patient's nutritional condition and breathing problems indicate the need for specialized palliative care. A relevant question is whether the competence and basic skills in palliative care are sufficient in the interprofessional teams. Data showed that members of an established team developed courage and strength, which were used in dialogue with patients regarding their prognosis. Several studies highlight challenging situations faced by patients with ALS, especially close to the end-of-life. ${ }^{[2,6,8]}$ This study supports the concept of "neuropalliative rehabilitation" ${ }^{[8]}$ and highlights the necessity of palliative competence, as well as competence, in caring for patients with ALS. According to Andersen et al. ${ }^{[6]}$ health personnel should initiate conversations concerning the endof-life and decisions regarding ventilator treatment. Hussain et al. ${ }^{[26]}$ emphasize the need to discuss questions regarding limitations to a normal life. Through conversations, the patient and their family can prepare for the final stages of the patient's life. Necessary priorities can be discussed, and wishes regarding the place of death clarified. Most often, the neurologist is also involved in this type of dialogue. Few patients with neurological diseases are offered palliative care from a specialist. However, there is increasing recognition of the fact that many patients with ALS need palliative care services. ${ }^{[26]}$ Data from this study shows that palliative care services are not sufficiently involved in interprofessional services to patients with ALS living at home in the palliative phase. According to Bede et al., ${ }^{[5]}$ most patients with ALS have no contact with palliative care. If patients are referred to palliative care services, this often happens late in the course of the disease. Several other studies suggest that palliative care, at a specialist level, should be present from the time of diagnosis. ${ }^{[6,8]}$ During the disease trajectory, health personnel are challenged to find the right time to provide the right information and talk about the coming requirements for care. Health personnel therefore need competence and courage in order to show flexibility at times. From other studies we have learned that the teams have reported certain approaches as successful in providing a safe climate for co-creation of expertise. ${ }^{[21,25]}$

This study suggests that interprofessional collaboration and the dissemination of knowledge and skills are two sides of the same coin. This is clearly expressed during interactions between municipal and specialist health personnel, when cooperation is based on the transfer of information, knowledge and skills. There is growing understanding of the fact that both service levels need to learn from each other, and that expertise is achieved through several sources. The combination of expertise creates better results than the sum from the individual disciplines. ${ }^{[4]}$ Further research should emphasize how to deal with the challenges organizing the co-creation between the municipality and specialist units for this particular target group.

\subsection{Strengths and limitations}

The strengths of this study is its broad experience conveyed by several professionals. The dynamics in the focus groups enable the participants to see different perspectives, which is an advantage using this methodological approach. However, the findings have to be interpreted with caution due to the limited sample size in this study.

\section{Conclusions}

Health personnel in municipal and specialist health care services view interprofessional team development as the basis for co-creation of services to patients with ALS living at home in the palliative phase. They emphasize the importance of processes that strengthen relationships and processes that connect different professionals and different expertise. The 
health personnel's experience regarding commitment and closeness to colleagues, patients, families and local networks provides opportunities for everyone involved to share expertise and be innovative together. Such innovation is linked to the concept of co-creation, which is influenced by, and in turn influences, structural frames, interprofessional teambuilding and the development of expertise and provision of palliative care - in the right place and at the right time. Cocreation happens in and between teams. When the patient is involved, valuable experience is exchanged. This supports cocreation of unique, individual and person-centered services, in addition to supporting the development of competence in interprofessional teams.

Regardless of those that are at any time involved as team members, on-going discussions about roles and the attainment of goals contribute to the establishment of flexibility and commitment. Flexible borders between municipal health service and specialist service provide opportunities for cooperation, innovation and co-creation of unique care for patients with ALS living at home.

\section{CONFlicts OF InTEREST Disclosure}

The authors declare that there is no conflict of interest.

\section{REFERENCES}

[1] Borasio GD, Miller RG. Clinical characteristics and management of ALS. Seminars in Neurology. 2001; 21(2): 155-66. PMid:11442324 http://dx.doi.org/10.1055/s-2001-15268

[2] Miller RG, Jackson CE, Kasarskis EJ, et al. Practice parameter update: the care of the patient with amyotrophic lateral sclerosis: multidisciplinary care, symptom management, and cognitive/behavioral impairment (an evidence-based review): report of the Quality Standards Subcommittee of the American Academy of Neurology. Neurology. 2009; 73(15): 1227-33. PMid:19822873 http://dx.doi.org/10.1212/WNL.0b013e3181bc01a4

[3] Chad DA, Bidichandani S, Bruijn L, et al. Funding agencies and disease organizations: resources and recommendations to facilitate ALS clinical research. Amyotrophic lateral sclerosis \& frontotemporal degeneration. 2013; 14 Suppl 1: 62-6. PMid:23678881 http://dx.doi.org/10.3109/21678421.2013.778588

[4] European Association for Palliative Care (EAPC). Definition of palliative care. 2010. Available from: http://www . eapcnet/eu/Cor porate/AbouttheEAPC/Definitionsandaims .aspx

[5] Bede P, Oliver D, Stodart J, et al. Palliative care in amyotrophic lateral sclerosis: a review of current international guidelines and initiatives. BMJ Supportive \& Palliative Care. 2011; 1(3): 3438. PMid:24653482 http://dx.doi.org/10.1136/bmjspcare .2010.232637.rep

[6] Andersen PM, Borasio GD, Dengler R, et al. Good practice in the management of amyotrophic lateral sclerosis: clinical guidelines. An evidence-based review with good practice points. EALSC Working Group. Amyotrophic lateral sclerosis: official publication of the World Federation of Neurology Research Group on Motor Neuron Diseases. 2007; 8(4): 195-213. PMid:17653917 http://dx.doi.org/10.1080/17482960701262376

[7] Hoffman JJ. Toward a better understanding of amyotrophic lateral sclerosis. Home Healthcare Nurse. 2008; 26(6): 33744. PMid:18562817 http://dx.doi.org/10.1097/01. NHH.00 00324305.71459 .81

[8] Ng L, Khan F, Mathers S. Multidisciplinary care for adults with amyotrophic lateral sclerosis or motor neuron disease. The Cochrane Database of Systematic Reviews. 2009; 4: Cd007425. http://dx .doi.org/10.1002/14651858.cd007425.pub2

[9] Dybwik K, Nielsen EW, Brinchmann BS. Home mechanical ventilation and specialised health care in the community: Between a rock and a hard place. BMC Health Services Research. 2011; 11:
115. PMid:21605365 http://dx.doi.org/10.1186/1472-696 3-11-115

[10] McCormack B, McCance TV. Development of a framework for person-centred nursing. Journal of Advanced Nursing. 2006; 56(5): 472-9. Epub 2006/11/03. http://dx.doi.org/10.1111/j.136 $5-2648.2006 .04042 . x$

[11] O'Brien MR, Whitehead B, Murphy PN, et al. Social services homecare for people with motor neurone disease/amyotrophic lateral sclerosis: why are such services used or refused? Palliative Medicine. 2012; 26(2): 123-31. http://dx.doi.org/10.1177/026921631 1398697

[12] Morgan DL, Bottorff JL. Advancing our craft: focus group methods and practice. Qualitative Health Research. 2010; 20(5): 579-81. http://dx.doi.org/10.1177/1049732310364625

[13] Malterud K, Ulriksen K. Obesity in general practice: a focus group study on patient experiences. Scandinavian Journal of Primary Health Care. 2010; 28(4): 205-10. http://dx.doi.org/10.3109/028 13432.2010 .526773

[14] Krueger RA, Casey MA. Focus groups: a practical guide for applied research. 5, editor. Los Angeles, California: SAGE Publications; 2015.

[15] Kvale S, Brinkmann S. Interviews. Learing the craft of qualitative research interviewing. Los Angeles, California: SAGE Publications; 2014.

[16] Malterud K. The art and science of clinical knowledge: evidence beyond measures and numbers. Lancet (London, England). 2001; 358(9279): 397-400. http://dx.doi.org/10.1016/S0140-673 6(01) 05548-9

[17] Malterud K. Qualitative research: standards, challenges, and guidelines. Lancet (London, England). 2001; 358(9280): 483-8. http: //dx.doi.org/10.1016/S0140-6736(01) 05627-6

[18] Graneheim UH, Lundman B. Qualitative content analysis in nursing research: concepts, procedures and measures to achieve trustworthiness. Nurse Education Today. 2004; 24(2): 105-12. PMid:14769454 http://dx.doi.org/10.1016/j.nedt.2003.10.001

[19] Wibeck V, Dahlgren MA, Öberg G. Learning in focus groups: an analytical dimension for enhancing focus group research. Qualitative Research. 2007; 7(2): 249-67. http://dx.doi.org/10.1177/1 468794107076023

[20] World Medical Association. Declaration of Helsinki. 1964. Available from: http://www.wma.net/en/30publications/10po licies/b3/ 
[21] Prahalad CK, Ramaswamy V. Co-creation experiences: The next practice in value creation. Journal of Interactive Marketing. 2004; 18(3): 5-14. http://dx.doi.org/10.1002/dir. 20015

[22] Bergdahl E, Benzein E, Ternestedt BM, et al. Co-creating possibilities for patients in palliative care to reach vital goals-a multiple case study of home-care nursing encounters. Nursing Inquiry. 2013; 20(4): 34151. PMid:23336338 http://dx.doi.org/10.1111/nin. 12022

[23] Bainbridge D, Brazil K, Krueger P, et al. Measuring horizontal integration among health care providers in the community: an examination of a collaborative process within a palliative care network. Journal of Interprofessional Care. 2015; 29(3): 245-52. PMid:25418319 http://dx.doi.org/10.3109/13561820.2014.984019
[24] Junger S, Pestinger M, Elsner F, et al. Criteria for successful multiprofessional cooperation in palliative care teams. Palliative Medicine. 2007; 21(4): 347-54. PMid:17656412 http://dx.doi.org/10. $1177 / 0269216307078505$

[25] Klarare A, Hagelin CL, Furst CJ, et al. Team interactions in specialized palliative care teams: a qualitative study. Journal of Palliative Medicine. 2013; 16(9): 1062-9. PMid:24041291 http://dx.doi . org/10.1089/jpm. 2012.0622

[26] Hussain J, Adams D, Campbell C. End-of-life care in neurodegenerative conditions: outcomes of a specialist palliative neurology service. International Journal of Palliative Nursing. 2013; 19(4): 162-9. http://dx.doi.org/10.12968/ijpn.2013.19.4.162 